\title{
Optimizing a Sensor to Detect Ammonium Nitrate Based IEDS in Vehicles Using Artificial Neural Networks
}

\author{
Bourdillon Omijeh, Akani Okemeka Machiavelli \\ Department of Electronics and Computer Engineering, University of Port Harcourt, Port Harcourt, Nigeria \\ Email address: \\ bourdillon.omijeh@uniport.edu.ng (B. Omijeh),mackyakani@gmail.com (A. O. Machiavelli)
}

To cite this article:

Bourdillon Omijeh, Akani Okemeka Machiavelli. Optimizing a Sensor to Detect Ammonium Nitrate Based IEDS in Vehicles Using Artificial Neural Networks. American Journal of Neural Networks and Applications. Vol. 5, No. 1, 2019, pp. 1-6. doi: 10.11648/j.ajnna.20190501.11

Received: April 12, 2019; Accepted: May 21, 2019; Published: June 10, 2019

\begin{abstract}
Ammonium nitrate based explosives are a choice weapon for many terrorist groups due to its ease in manufacturing and high velocity of detonation. These explosives undergo thermal decomposition to release ammonia gas in traces of about 5- 25 Parts per Million (PPM) below the olfactory threshold. Ammonia is a reducing gas. MQ137 sensors are low cost commercially available metal oxide semiconductor ammonia gas sensors with a problem of selectivity (reacting with other reducing gasses like carbon monoxide etc) and sensitivity. We present the optimization of MQ137 metal oxide semiconductor electrochemical sensor using MATLAB, to improve its selectivity and sensitivity for accurately recognizing the characteristics of ammonia gas within specified PPM range as a sign of ammonium nitrate based explosives in vehicles. In this study, MQ137 sensor was connected with an ARDUINO microcontroller to a digital computer (2.40 GHz processor) and preheated for 12 hours before being exposed to ammonia gas in a controlled environment at room temperature to extract features (sensitivity constant and concentration in PPM) of ammonia gas with MQ137 sensor. 150 data samples of each feature were extracted and trained in a multilayer pattern recognition neural network with one hidden layer and 50 data samples containing features of other reducing gasses from the data sheet were used for testing. Test performance of multilayer artificial neural network has an accuracy of $100 \%$ with no misclassifications.
\end{abstract}

Keywords: IED Detection, MQ137 Sensor, Neural Networks, Ammonia Gas, Optimization, PPM

\section{Introduction}

In Africa and Nigeria, particularly the northern Nigeria where the activities of Boko-Haram insurgents (a terrorist group) are prevalent, the use of ammonium nitrate based improvised explosive devices is common. This is due to the availability of the chemical compounds for manufacturing these explosives and the ease at which they are manufactured. These explosives were initially used for rock blasting and mining activities [1]. They are made locally from chemical compounds and fertilizers which are easily gotten due to the prevalence of farming in northern Nigeria, the resulting mixture gives Ammonium nitrate fuel oil (ANFO) explosive when dry [2]. This is the major aim of using a sensor to detect the properties of ANFO since the sensor is readily available, affordable and offers a viable alternative in overcoming current challenges in the field.

MQ137 sensors have tin oxide $\left(\mathrm{SnO}_{2}\right)$ as their sensing compound and when heated, its free electrons increase thereby decreasing its resistance. In the presence of fresh air (oxygen), these free electrons are absorbed by oxygen molecules which are oxidizing agents to increase its resistance and thus no conduction. When in the presence of a reducing gas (e.g, $\mathrm{CO}, \mathrm{NH} 3$, etc), the oxygen molecule on the surface of the tin oxide sensor gets desorbed by the reducing gasses thus decreasing the resistance of the sensor.

MQ137 sensors have a problem of selectivity, in that they react with similar reducing gasses thus increasing the rate of false alarm [3-6].

Many applications of tin oxide sensors for detection of ammonia or other gasses have used several MQ-series sensors, like Silva et al developed a tin oxide sensor to detect ammonium nitrate based IEDs as a first step in detecting these explosives (ANFO) and proposed the use of an additional sensor which would detect diesel, to confirm the presence of these explosives. This was because of the selectivity problem of these sensors and several means have been proposed to improve its selectivity [7-10]. Dogs have 
also been used to detect these explosives over time but this remains an expensive option, training and feeding these dogs is capital intensive.

With all being said we optimize MQ137 sensors to improve its selectivity and sensitivity for detecting ANFO explosives in vehicles at concentrations of 5- 25 PPM range which is below the olfactory threshold [2].

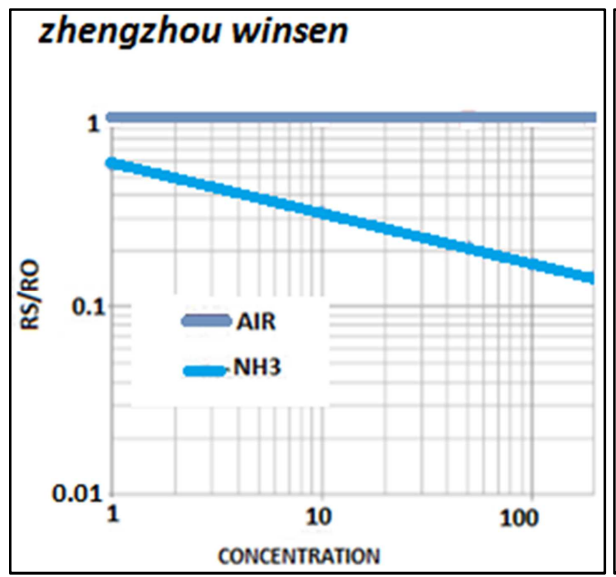

\section{Extracted Features}

MQ137 sensors are produced by different manufacturers and thus slightly differ in their sensitivity characteristics as a result of differences in doping the semiconductor and different testing conditions. Typical sensitivity characteristics of the sensor from two manufacturers are compared below.

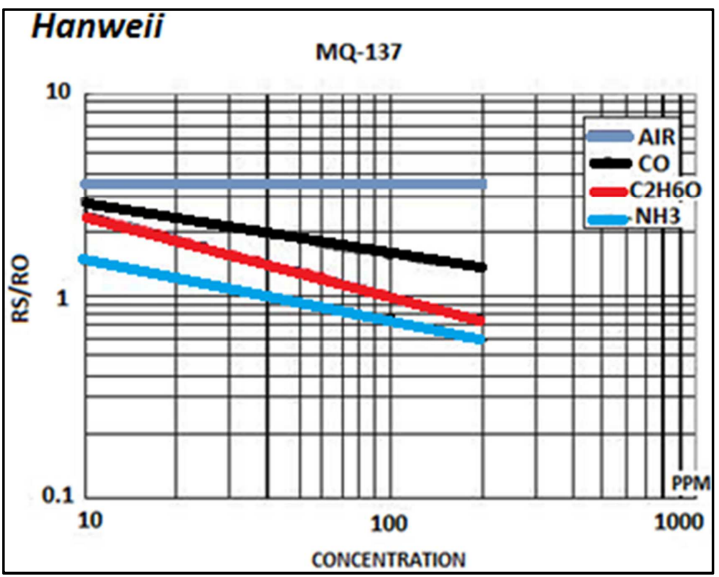

Figure 1. Comparing Characteristics of MQ137 sensor with Ammonia from Zhengzhou WINSEN and HANWEII electronics companies respectively [6, 11].

From the datasheets above, the $\mathrm{X}$-axis is concentration in $\mathrm{PPM}$ against sensitivity constant $(\mathrm{RS} / \mathrm{RO})$ on the $\mathrm{Y}$-axis. The sensitivity constant of MQ137 falls within different ranges for each reducing gas. These differences are directly proportional to their relative densities in air. Since ammonia gas is light and diffuses faster in air than carbon monoxide (CO) and other reducing gasses, which makes the tin oxide sensing element more sensitive to it than other reducing gasses.

The MQ137 sensor used in this study was from ZHENGZHOU WINSEN electronic company Ltd and for our application range of 5-25PPM concentration, constant sensitivity range of MQ137 sensor for ammonia gas falls within 0.3 and 0.7 which is unique to only ammonia gas and thus we extract data samples of both features (concentration in PPM and Sensitivity constant) for training the neural network.

ARDUINO will be used to extract these features from an MQ137 sensor manufactured by ZHENGZHOU WINSEN electronics company LTD [6, 12-13].

Neural networks will be trained to recognize this constant sensitivity range at the required concentration range in PPM as a sign of ammonia gas, and every other value outside this range will be seen as noise. In that way the selectivity of the sensor will be improved. Just as Humans are able to recognize numerous patterns, like recognizing a face in the dark because they have seen it before, differentiating between different colors etc [12-14].

\section{Materials and Methods}

The materials used were acquired and setup to extract features of ammonia gas with MQ137 sensor for optimization using pattern recognition in neural networks.

\subsection{Feature Extraction Prototype Setup}

The materials used are:

i. ARDUINO Microcontroller with ARDUINO 1.8.5 Integrated Development Environment (IDE).

ii. MQ137 sensor module from ZHENGZHOU WINSEN Electronics Company.

iii. Jumper wires, breadboard, buzzer, display and a $47 \mathrm{~K}$ ohms resistor to maximize the sensitivity of the sensor in order to detect ammonia at lower PPM range.

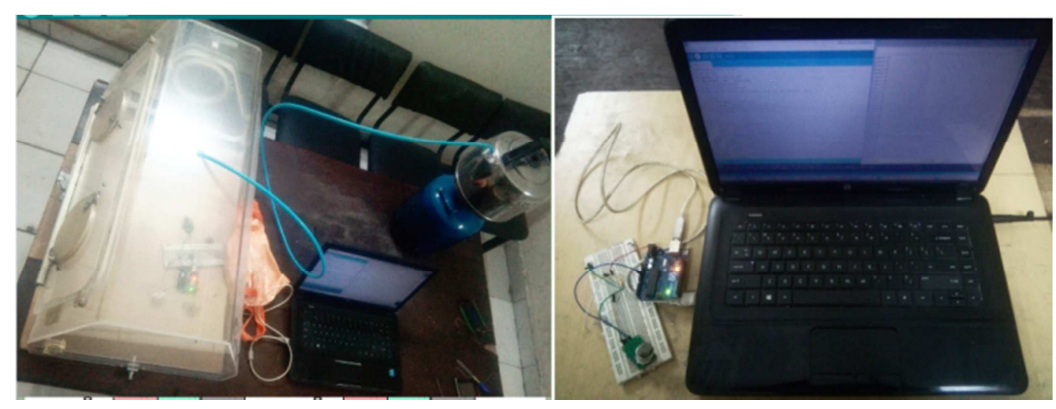

Figure 2. Prototype setup. 
The digital computer was used to program the arduino microcontroller and preheat the MQ137 SENSOR for 12 hours before exposing it to ammonia gas (heated mixture of calcium and ammonium hydroxide chemicals) at room temperature. The ARDUINO codes for extracting these features are open source an can be gotten at Jaycon systems.[12]

\subsection{Artificial Neural Network Classification}

150 data samples of the extracted features were collected via the serial monitor of the arduino IDE and used to train the neural network, Also 50 samples of noise (values from other reducing gasses, especially carbon monoxide) were used to test the network. Artificial neural network was employed as the classifier to design a classification model. The two parameters provided to the classifier showed the number of classes in the dataset (which is two in our dataset, one for each feature) and the second parameter informs the classifier about the number of features used. The classifieris designed to train the database and evaluate the test performance of the network, achieved using pattern recognition toolbox in matlab.

The basic artificial neural network is made of two layers, a hidden and an output one. The input neurons are the exact number of features vector (200 in total, that is 150 for training and 50 noise vector signals for testing). According to the number of features extracted for ammonia gas, the input neurons are 2 , and the input vector is 200-by-2. Only one hidden layer with 10 neurons was taken which gave the best performance for the study. Also it was proven by Hecht-Nielsen that a neural network with ine hidden layer can carryoutthe approximation ofany function [15]. The neurons of the output system are 2 as our classification has two features (sensitivity constant and concentration in PPM). The training algorithm used for the artificial neural network was Scaled Conjugate Gradient.

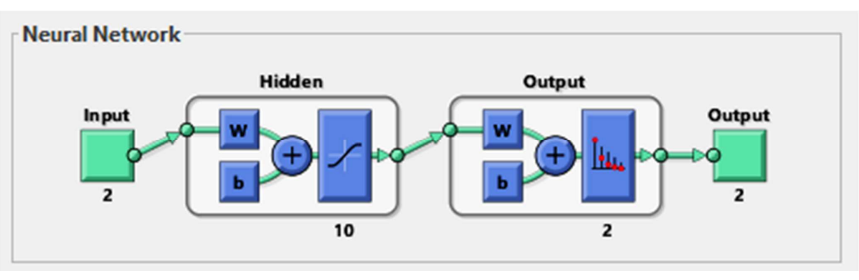

Figure 3. Block diagram of pattern recognition in neural network.

The output matrix format is a combination of the 200-by-2 binary matrix as shown in the table below, presence of ammonia gas corresponding binary output will be $\left(\begin{array}{ll}1 & 0\end{array}\right)$ and other gasses binary matrix format $\left(\begin{array}{ll}0 & 1\end{array}\right)$.

Table 1. Output Format of neural network.

\begin{tabular}{lll}
\hline Rows & Ammonia gas & Other gasses \\
\hline Ammonia gas & 1 & 0 \\
Other gasses & 0 & 1 \\
\hline
\end{tabular}

\section{Results}

\subsection{Extracted Features from Arduino IDE}

The samples extracted from the arduino serial printer showing the detected PPM and RS/RO values (i.e Concentration and Sensitivity Constant respectively) are shown below with their respective codes. It should be noted that these values were gotten after the sensor has been pre heated for over 12 hours and they fall within the required value range from the datasheet $(0.3-0.7$ for Sensitivity constant and 5-25 PPM for Concentration).

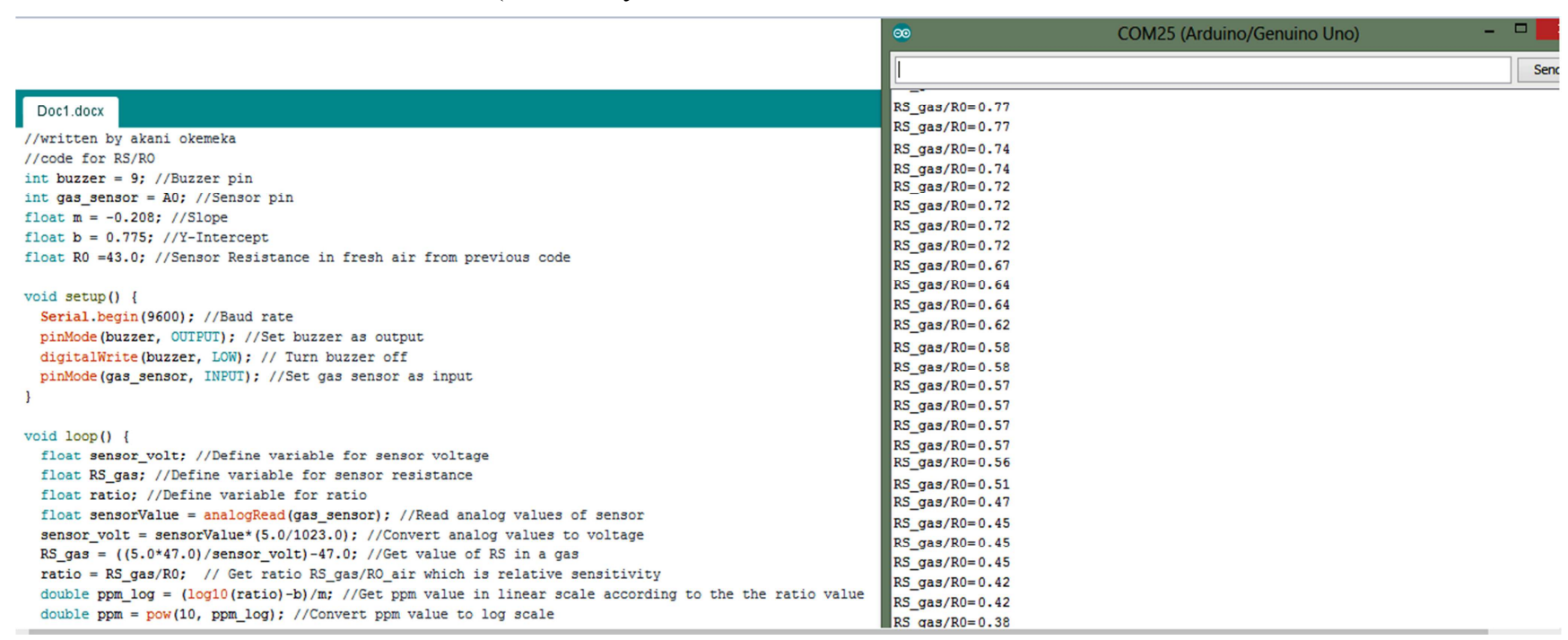

Figure 4. Showing Sensitivity Constant sample data of the sensor in the presence of ammonia gas. 


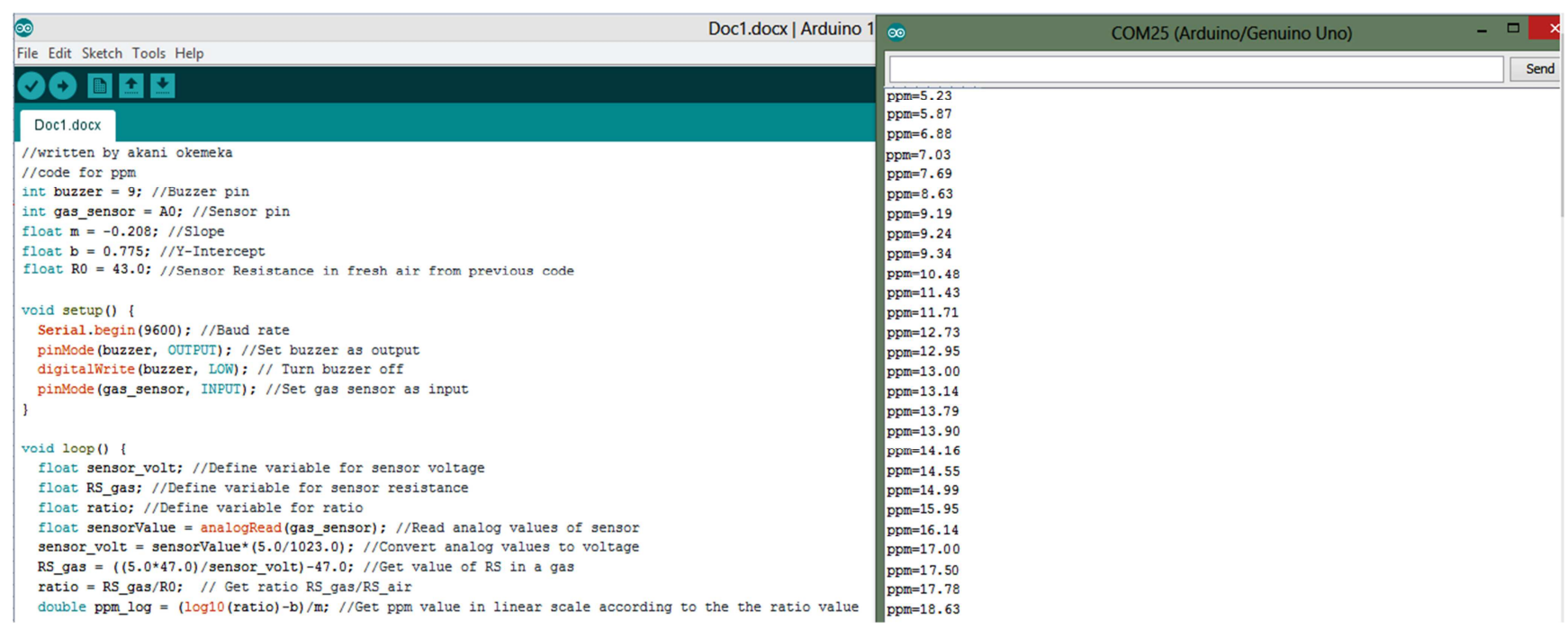

Figure 5. The concentration values in PPM of sensor in presence of ammonia gas.

\subsection{Pattern Recognition Neural Network}

The results from the neural network optimization are presented as follows:

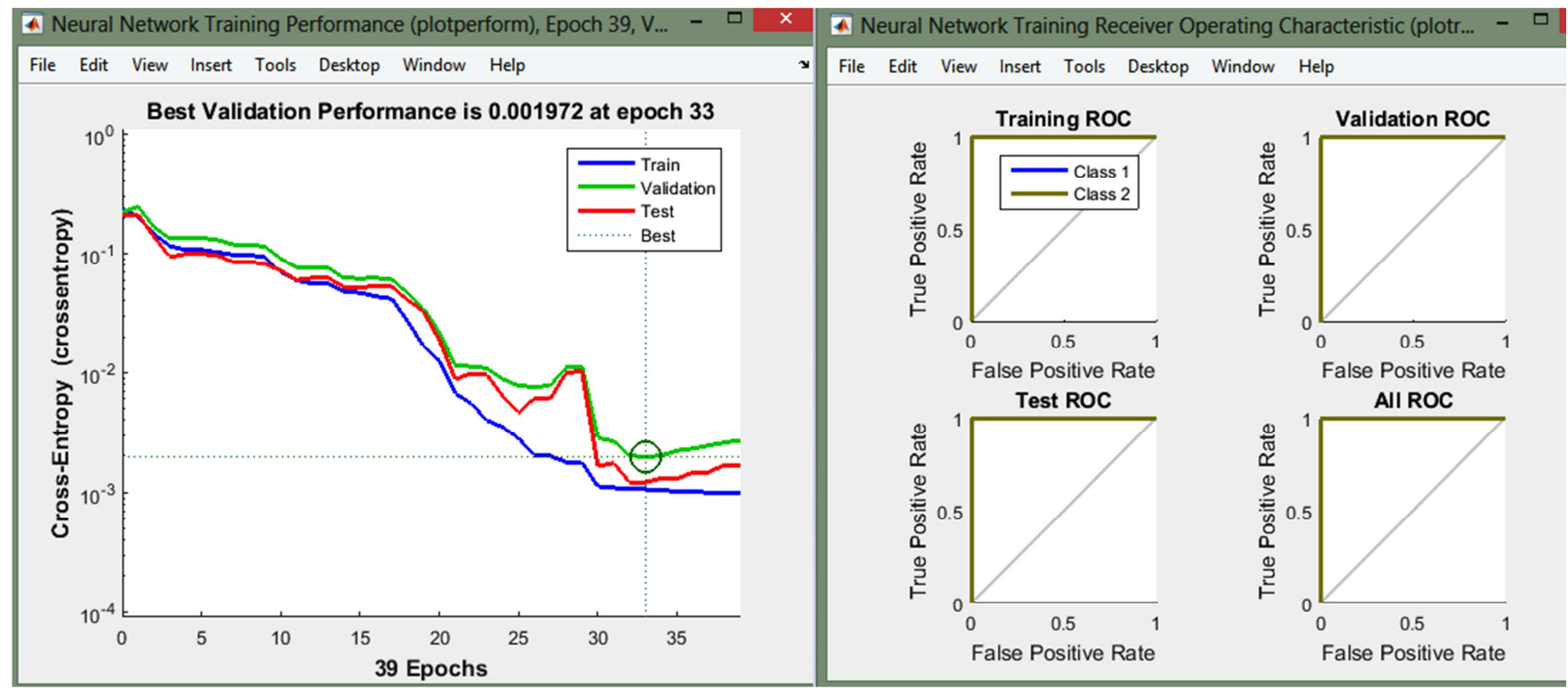

Figure 6. Simulation performance plot and receiver operating characteristics.

During the training stage, the training, validation and test data were distributed in percentages to avoid network over fitting problem. The 200 samples were randomly divided and $70 \%$ (140 samples) were used for training, 15\% (30 samples) each were used for validation and testing. Validation samples were used to halt the training when there are no further improvements. The testing samples have no direct influence on training but provide an individual assessment of the training. At the start of training process, cross-entropy error was maximum, the neural network optimized the error at every iteration and at epoch 33 the network gave the best validation performance where cross-entropy error was 0.001972 . The receiver operating characteristics curve shows the true positive versus the false positive as the threshold is varied. In the upper left corner of the receiver operating characteristics, the sensitivity and selectivity were both $100 \%$ for this problem and it shows that the system performs very well. 


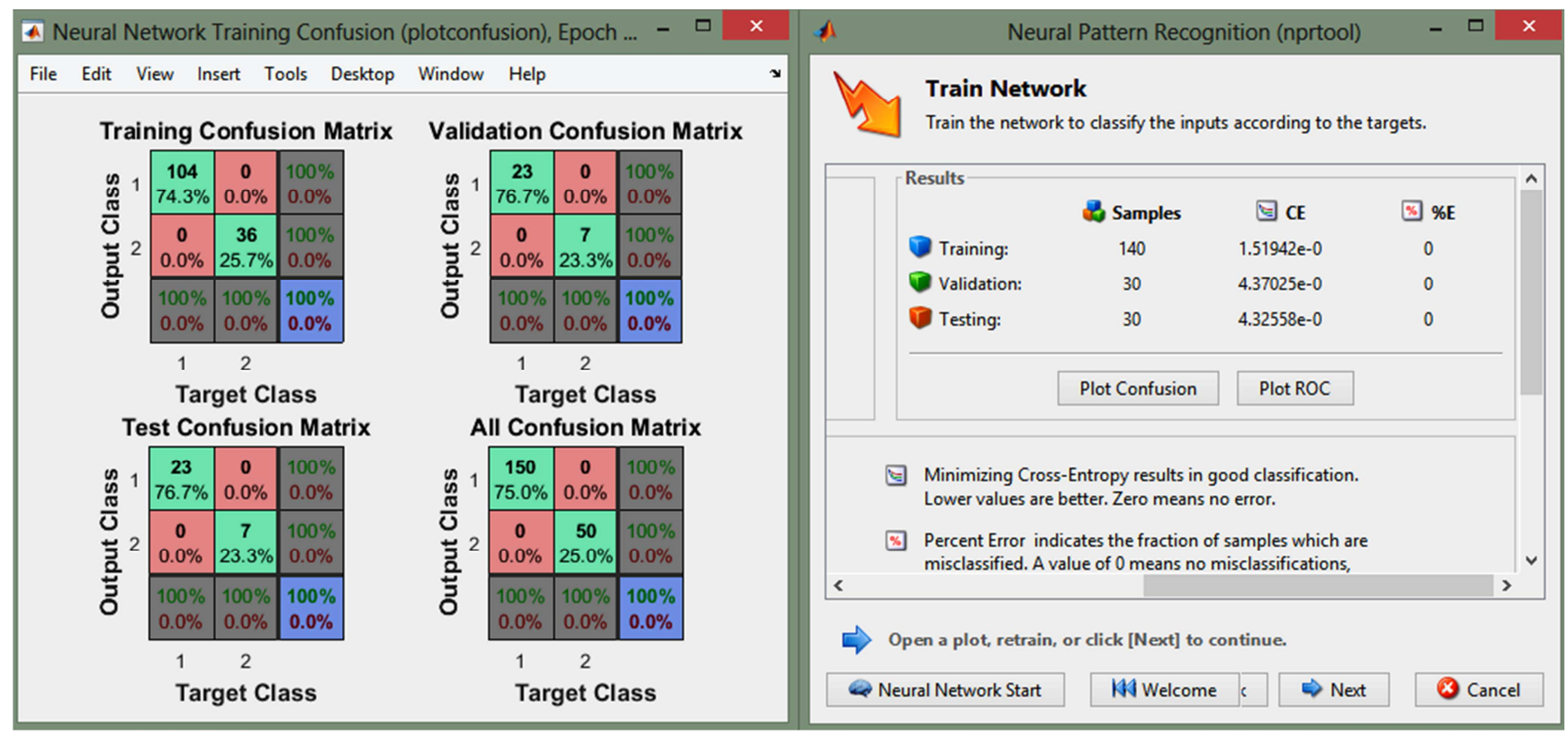

Figure 7. Artificial Neural Network Training Confusion Matrixes and Result.

From the diagonal matrix, $100 \%$ of the cases (all 200 samples) were correctly classified and no cases were misclassified. The training result shown above has minimum cross entropy (CE) which signifies a very good classification. The zeros mean that no error existed in the classifications. Percent error $(\% \mathrm{E})$ indicates the portion of samples which were misclassified during training, and the zero (0) values means there were no misclassifications.

\section{Conclusion}

The proposed method used the datasheet for its feature extraction process. The classifier used was artificial neural networks with an overall classification accuracy of $100 \%$. With such accuracy the problem of sensitivity and selectivity of MQ137 sensor has been enhanced. Silva et al proposed the use of two semiconductor gas sensors to confirm the presence of an ammonium nitrate based explosive due to its problem of sensitivity and selectivity. Therefore it can be concluded that with neurons trained to classify these patterns and discriminate between ammonia and other reducing gasses (seeing them as noise), our detection system has been greatly optimized and is suitable for detecting traces of ammonia gas as a possible sign of ammonium nitrate based explosives in vehicles.

\section{References}

[1] E. G. MAHADEVAN, AMMONIUM NITRATE EXPLOSIVES FOR CIVIL APPLICATIONS, 1ST ED., SINGAPORE: WILEY-VCH, 2013.

[2] SUSANA M. SILVA, JORGE D. GAMARRA, CÉSAR A. HERNÁNDEZ, JOHANN F. OSMA, "DESIGN AND FABRICATION OF A SENSOR FOR EXPLOSIVES AS A FIRST STEP TO AN IED DETECTION DEVICE.," IEEE JOURNAL, 2014.
[3] R. D. DELGADO, "TIN OXIDE GAS SENSORS: AN ELECTROCHEMICAL APPROACH," UNIVERSITY OF BARCELONA PRESS, BARCELONA, SEPTEMBER 2002.

[4] L. D. A. A. N. MINNAJA, "SENSITIVITY AND SELECTIVITY OF A THIN-FILM TIN OXIDE GAS SENSOR," SENSORS AND ACTUATORS B, PP. 197-204, 1991.

[5] ATA JAHANGIR MOSHAYEDI ET AL, "MATHEMATICAL MODELLING FOR $\mathrm{SNO}_{2}$ GAS SENSOR BASED ON SECOND-ORDER RESPONSE," IN IEEE SYMPOSIUM ON INDUSTRIAL ELECTRONICS \& APPLICATIONS, KUCHING, MALAYSIA, 2013.

[6] L. ZHENGZHOU WINSEN ELECTRONICS TECHNOLOGY CO.. [ONLINE]. AVAILABLE: WWW.WINSEN-SENSOR.COM.

[7] MANN D. P., PRATT K. F. E., PARASKEVA T., PARKIN I. P., METAL OXIDE SEMICONDUCTOR GAS SENSORS UTILISING MODIFIED ZEOLITE CATALYSTS TO IMPROVE SELECTIVITY, IEEE PROCEEDING, PP 184$187,2014$.

[8] R. S. FALCONER, R LEC, J. F. VETELINO AND Z. XU, OPTIMIZATION OF A SAW METAL OXIDE SEMICONDUCTOR GAS SENSOR, ULTRASONICS SYMPOSIUM, PP 585-590, 1989.

[9] J. FRANK, M. FLEISCHER, H. MEIXNER, A. FELTZ, ENHANCEMENT OF SENSITIVITY AND CONDUCTIVITY OF SEMICONDUCTING $\mathrm{GA}_{2} \mathrm{O}_{3}$ GAS SENSORS BY DOPING WITH $\mathrm{SNO}_{2}$.

[10] ERIC N. DATTOLI AND KURT D. BENKSTEIN, IMPROVING THE SELECTIVITY OF A METAL OXIDE NANOWIRE GAS SENSOR USING A MICROHOTPLATE/FET PLATFORM, INTERNATIONAL SUSTAINABLE DEVELOPMENT RESEARCH SOCIETY (ISDRS), 2011.

[11] L. HANWEI ELECTRONICS CO.. [ONLINE]. AVAILABLE: HTTP://WWW.HWSENSOR.COM. 
[12] "JAYCON SYSTEMS," [ONLINE]. AVAILABLE: WWW.JAYCONSYSTEMS.COM/TUTORIALS/GASSENSORS.

[13] J. HOFFMAN, MASTERING ARDUINO; A PROJECT BASED APPROACH TO ELECTRONICS, CIRCUITS, AND PROGRAMMING, BIRMINGHAM, UK: PACKT PUBLISHING LIMITED, 2018.

[14] S. HAYKIN, NEURAL NETWORKS AND LEARNING
MACHINE, THIRD EDITION ED., ONTARIO, CANADA: PEARSON EDUCATION INCOPORATED, 2009.

[15] KH TOHIDUL ISLAM, GHULAM MUJTABA, DR. RAM GOPALRAJ, HENRY FRIDAY NWEKE, HANDWRITTEN DIGITS RECOGNITION WITH ARTIFICIAL NEURAL NETWORK, INTERNATIONAL CONFERENCE ON ENGINEERING TECHNOLOGY AND TECHNOPRENEURSHIP (ICE2T), 18-20 SEPTEMBER, KUALA LUMPUR, MALAYSIA, 2017. 